\title{
Modeling of Magnetizing Inrush and Internal Faults for Three- Phase Transformers
}

Farhad Namdari, Mohammad Bakhshipour, Behroz Rezaeealam, Mohammad Sedaghat
Department of Electrical Engineering, Faculty of Engineering, University of Lorestan, khorramabad, Iran

\begin{tabular}{l}
\hline \hline Article Info \\
\hline Article history: \\
Received Jun 6, 2017 \\
Revised Aug 19, 2017 \\
Accepted Aug 23, 2017 \\
\hline
\end{tabular}

\section{Keyword:}

3-dimensional model of three-

Phase transformer

Finite element

Internal short circuit faults

Magnetizing inrush

\begin{abstract}
Among the most noticeable root causes of improper performance in power transformers, internal short circuit faults can be noted and if not quickly be identified and addressed in the accepted time interval, irrecoverable damages such as interruption or even collapse of the network connected to the power transformer would happen. In this contribution, three-phase transformer behaviors under magnetizing inrush, internal short circuit condition and their current values determination have been surveyed using electromagnetic coupling model approach and structural finite element method. Utilizing the definition of transformer in the form of multi-coil and their electromagnetic and electric couple, a three dimensional geometric model of transformer is developed which includes nonlinear characteristics of the transformer, different states of normal and under internal short circuit occurrence and the moment of magnetizing inrush creation are investigated. The comparison between obtained results of presented model simulation with the consequences of practical studies on a typical three phase transformer reveals that the proposed model has a reliable accuracy in detection and modelling the transformer behavior in normal conditions, magnetizing inrush and different types of internal faults. The proposed approach represents an accurate model of a three-phase transformer for protection aims.
\end{abstract}

Copyright $@ 2017$ Institute of Advanced Engineering and Science. All rights reserved.

\section{Corresponding Author:}

Mohammad Bakhshipour,

Department of Electrical Engineering,

Faculty of Engineering, University of Lorestan,

Khorramabad, Iran.

Email: bakhshipour_m@yahoo.com

\section{INTRODUCTION}

Power transformers are of the most important elements in power systems. Therefore, monitoring their operation in normal and fault conditions, in addition to their importance in different evaluations and calculations in power system, can guarantee the proper operation for protection system. Thus, this prevents irreparable damages to power transformer and its connected network. Between 70 to 80 percent of transformer damages are caused by winding short circuit faults [1]. In this view point, this is important to achieve a model for transformer which can justify its behaviour in fault conditions. Winding-to-winding faults are also produced by reasons like mechanical force due to a mechanical connection in transformer, winding insulation destruction caused by continuous overload and transformer insulation breakdown due to an impulse voltage, or combination of all the mentioned reasons [2-3].

The transformer models used in most previous studies are in no-fault cases or models those consider external fault [4-5]. In [6-8], by making short circuit connections of the main nodes which belong to a winding, a new protection-based method is investigated for modelling and simulating internal short circuit faults in transformers. In [9], an advanced algorithm is proposed in which the power transformers protection is shown on a single-phase transformer by an equivalent circuit of inverse inductances. In [10-11], one of the most important models is proposed that obtains leakage and linkage inductance and also resistance matrices 
to internal fault studies. Therefore a linear model for transformer with internal fault is achieved. But this mentioned algorithm is not precise enough in transformer modelling in comparison with the other transformer protection algorithms [12-13].

In [14-15], to facilitate the calculations and increase the accuracy of the winding short circuit faults modelling procedure, a model known as the variable phase model has been introduced. This model employs the winding linkage fluxes as solution variables. Another research uses Transmission Line Method (TLM) and fuzzy logic analysis based on dynamic principle component analysis in modelling of transformer behavior for internal short circuit studies [16].

Finite Element Analysis (FEA) is another technique for precise modelling of elements behavior such as power transformers which have nonlinear characteristics like magnetic saturation [19-20].

In [18], the two dimensional model of finite element method is presented for investigating the behavior of transformer. In this model, due to eliminating one dimension, in order to proper approximation, the lost value of coil should be applied in electrical model of transformer. So this model cannot be considered as an accurate model for transformer.

In this paper, by using electromagnetic coupling model and three-dimensional structural finite element, a power transformer modelling is presented in different conditions including normal condition, magnetizing inrush and internal short circuit fault cases.

In this approach, a multi-coil form is considered for the transformer and with electromagnetic and electric couple between coils; a physical and geometric model of transformer is constructed. Also, different field and terminal parameters of transformer in the normal condition and internal short circuit cases, are obtained very accurately with evaluating done by time step method. This model also considers the transformer nonlinear characteristic.

\section{INTERNAL FAULTS IN TRANSFORMERS}

Internal short circuit faults are known as most important reasons of inappropriateness performance in power transformers. Also, distinguishing the fault from magnetizing inrush effect of the transformer is so significant to guarantee the robust protection of wind to wind fault in the primary phase and at last, it depicts the primary to secondary winding fault. In ground faults, the winding is divided into two -N1 and N2- parts [11]. Figures 1(a), 1(b), 1(c), and 1(d) depict equivalent circuits states of the transformer normal condition, short circuit fault in primary phase, turn to turn fault in primary phase and primary phase turn to secondary phase turn fault, respectively.

On the other hand, in turn to turn faults, the winding is divided to three $-\mathrm{N} 1, \mathrm{~N} 2$ and N3- parts. Finally in two winding faults, each winding is divided to two parts. All the mentioned faults shall be considered for 3 phases. Also, the simultaneity probability of the faults is possible. Now, the most important problem is evaluating and obtaining the relationships of transformer in these conditions (internal faults) while considering transformer characteristics such as leakage and mutual inductances and their mutual impacts, nonlinear B-H curve, change in load and change of source impedance.

During network reconfiguration, the power flow analysis should be performed. For each proposed configuration, the power flow analysis should be implemented to evaluate the nodal voltage, power loss of system and current of each branch. Due to several advantages of the forward/backward sweep technique such as. Needing low memory, high computational performance, simple structure, high convergence capability, and applicability to utilization in unbalanced systems, this power flow method has been selected in this study [10].

\section{POWER TRANSFORMER MODELING BASED ON FINITE ELEMENT METHOD}

\subsection{General Principles}

Finite element method is a numerical technique to obtain approximate solutions in boundary value problems and because of its high ability in analysis of so-complicated geometric and composite problems, this method is an important tool in solving electromagnetic problems. General principles in three-dimensional finite element analysis for transient assessment of the power transformer behavior with coupled electrical and electromagnetic field are based on Maxwell's equations (1-2).

$$
\begin{aligned}
& \nabla *\left(\frac{1}{\mu} \nabla * \vec{A}\right)+\sigma\left(\frac{\partial}{\partial t} \vec{A}+\nabla \mathrm{V}\right)=\mathrm{J}_{\mathrm{s}} \\
& \nabla \cdot \mathrm{A}=0 \\
& {\left[\mathrm{E}_{\mathrm{m}}\right]=\left[\mathrm{R}_{\mathrm{m}}\right]\left[\mathrm{I}_{\mathrm{m}}\right]+\mathrm{N} \frac{d}{d t}[\varphi \mathrm{m}]+\left[\mathrm{L}_{\mathrm{m}}\right] \frac{d}{d t}\left[\mathrm{I}_{\mathrm{m}}\right]}
\end{aligned}
$$


$\mathrm{N}$ these equations, $\sigma$ represents electrical conductivity of the related domain, $\mu$ is magnetic permeability, A, magnetic potential vector, $\mathrm{J}_{\mathrm{s}}$, current source density and $\mathrm{V}$ is the electrical scalar potential whose gradient value in each surface could be evaluated if the injected electrical voltage to that surface has been determined. The third relation states $\mathrm{m} t h$ electrical branch equations. In these matric terms, $\varphi m$ is magnetic flux between windings, $\mathrm{N}$ is number of turns, $\mathrm{E}_{\mathrm{m}}$ and $\mathrm{i}_{\mathrm{m}}$ are applied voltage and electrical current in $\mathrm{m}$ th branch, respectively. $\mathrm{R}_{\mathrm{m}}$ and $\mathrm{L}_{\mathrm{m}}$ matrices indicate branch resistance and branch leakage inductances, respectively [21-22].

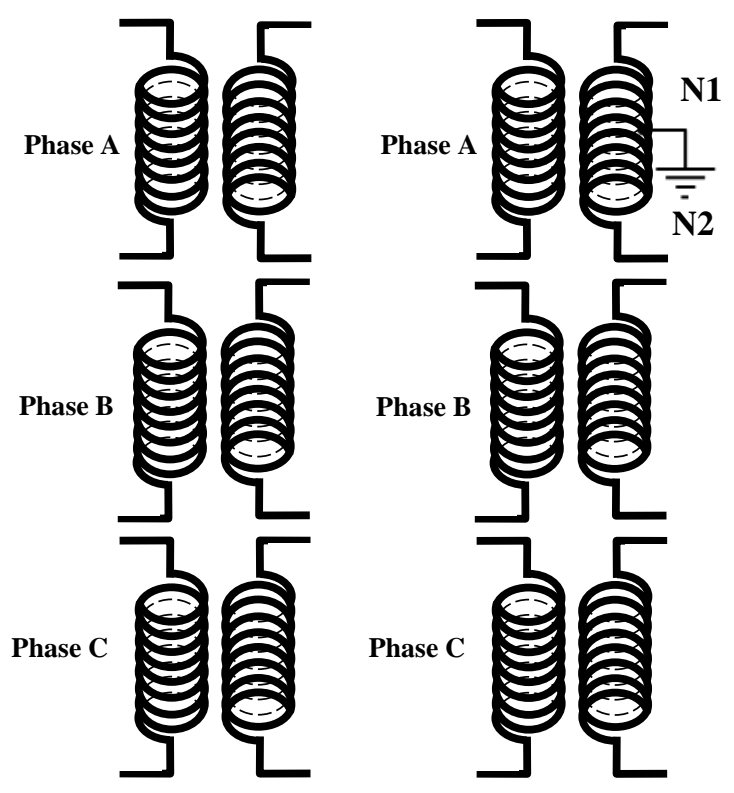

(a)

(b)

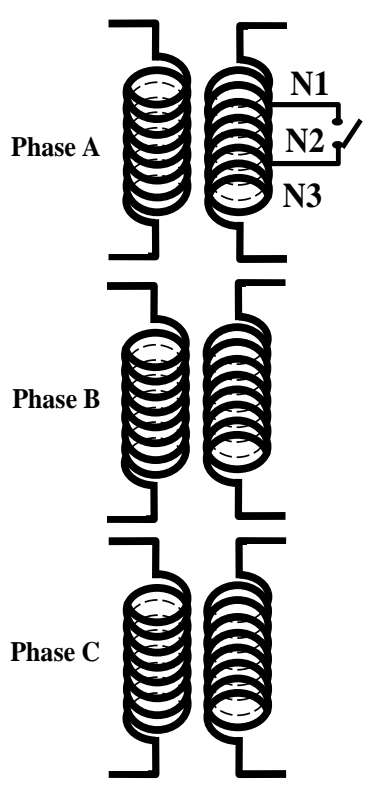

(c)

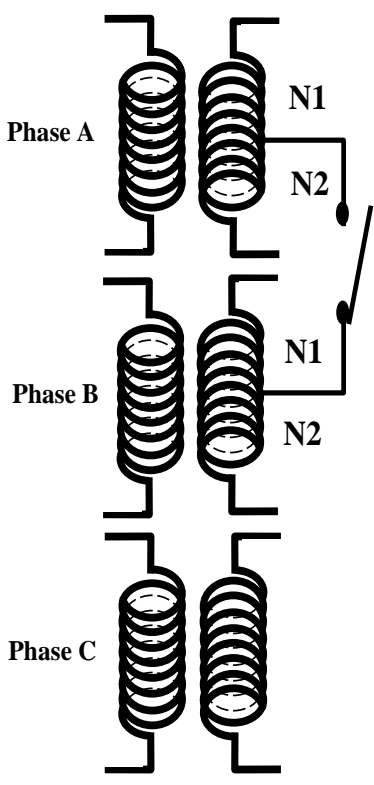

(d)

Figure 1. Model of Transformer Circuit Area Under Internal Short Circuit Fault. (A) No Fault Condition, (B) Single Phase to Ground Short Circuit Condition, (C) Turn to Turn Short Circuit Condition, (D) The Turns

Connection of Phase a to Phase B

With taking the above mentioned equations into account, the information related to the geometrical structure of transformer, boundary conditions, core and windings characteristic (including non-linear characteristic of the core), and supply conditions and loading are considered as problem inputs and some different quantities such as windings electrical current and internal field quantities distribution of transformer are supposed as the outputs of the model. These equations describe the transformer electromagnetic equation as a second order differential equation and on the condition that the divergence of magnetic potential vector (coulomb gauge) is equal to zero, guarantee the unique solution of magnetic potential vector in problem nodes.

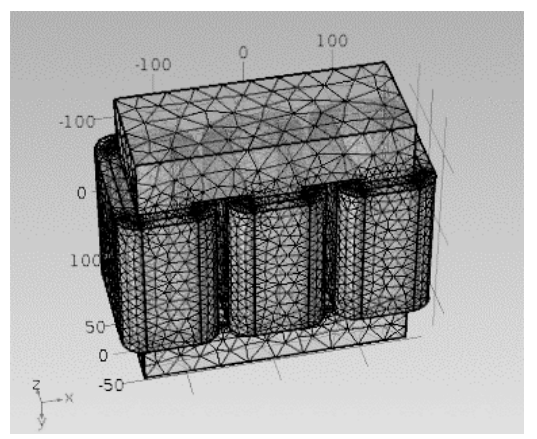

Figure 2. Mesh of the Studied Transformer 
Each set of the electrical and magnetic equations of transformer in the above equations makes its own corresponding matric equation and with coupling these equations and solving them by discretion the space of problem into a few components known as mesh (Figure 2) and calculating the potential vector in each node, the problem would be solved and all the electrical and magnetic quantities could be described based on these parameters.

Considering this fact that the above mentioned equations are Maxwell equations and valid in all electromagnetic systems regardless of their conditions and structures, in the fault occurrence condition, these equations could clarify the electrical and magnetic behavior of transformer [20].

\subsection{Modeling and Simulation of Transformer}

\subsubsection{Modeling Magnet}

In order to validate the proposed approach, it is implemented on a real transformer. The transformer characteristics are shown in Table. 1. The studied transformer is depicted in Figure 3. The finite element modelling of transformer contains three general steps: 1- magnetic core modelling, windings modelling, the insulation space between them with proper geometry, and assigning appropriate values to the constitutive parameters of elements such as conductivity, permeability coefficient, and passing coefficient for each element. 2-triggering the model in order to adjust initial condition and 3-performing proper boundary conditions to the problem. In order to reduce the amount of calculations, symmetry in Comsol Multiphysics 5.1 software is used. In Figure 4, the air is modelled around the transformer and using symmetry also caused reduction in calculations. In the length of $\mathrm{z}$, y axis, using symmetry is feasible and as shown in Figure 4, the space of problem has been diminished.

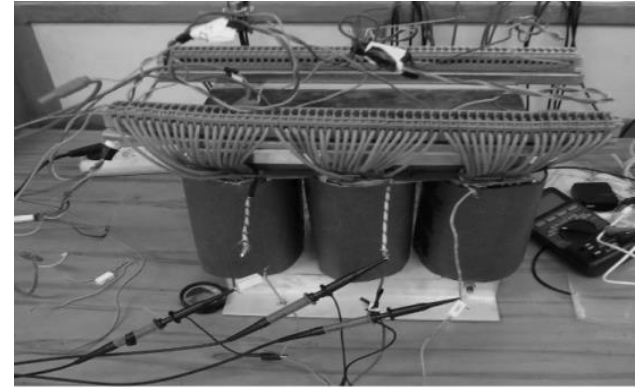

Figure 3. Physical View of the Studied Transformer

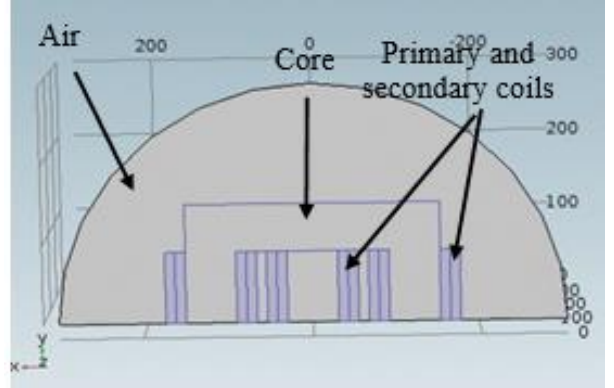

Figure 4. Finite Element Model of the Studied Transformer

Table 1. Charactristics of the Studied Transformer

\begin{tabular}{cc}
\hline rated power & $10 \mathrm{kVA}$ \\
\hline ratio & $200 / 200$ \\
HV turns number & 266 \\
LV turns number & 266 \\
connection group & Yy0 \\
core's diameter & $120 \mathrm{~mm}$ \\
coil's diameter & $2.1 \mathrm{~mm}$ \\
\hline
\end{tabular}

\subsection{Faults Modeling}

\subsubsection{Magnetic Model}

Figure 5 illustrates finite element model of transformer when turn to turn fault is accrued in the primary side. In this modelling, because the cross-sections of conductors are considered less than conductor skin depth, the eddy losses could be neglected. The basis of this model is similar to one that presented in [12] in which the divided windings method is used in short circuit fault condition in order to investigate transformer behavior. Therefore, with variation in considered short circuit resistance in a specific time and noticing the exact definition of connection mesh numbers, the short circuit conditions could be performed to transformer. In other words, the transformer can be modeled with electrical-magnetic coupling and divided windings and in a specific time and the variations related to the fault resistance are performed. It should be noted that in the previous finite element-based models, the electrical current density was used as problem input [19]. 


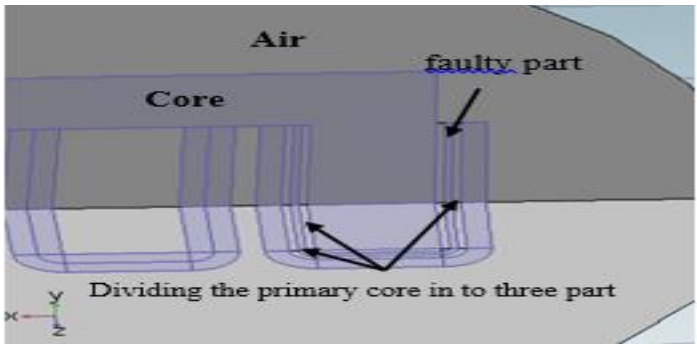

Figure 5. Finite Element Model of the Studied Transformer. (A) Core, (B) Primary Coil, (C) Healthy Part of Faulty Coil and Short Circuit Part of The Faulty Coil (D)

It means in short circuit fault condition, the faulty winding has current density and the others become open circuit. With knowing the value of density current, electromagnetic equations have been solved. But because the following electrical current density in the connection meshes is a function of total winding density current and fault condition (location and number of containing turns), also current and total magnetic motivation force (MMF) of winding are dependent on the fault condition, so these models could not be practical.

Also, it should be noted that in this paper, with utilizing finite element approach, different field parameters and terminal behavior of transformer in the winding short circuit condition are calculated through COMSOL Multiphysics software [23]. In addition to having an ability of calculation and investigation of magnetic characteristics of the studied model, this software can simulate the terminal quantities behavior of the model. Thus, using ancillary software to connect electrical circuits (including supply and loading) and magnetic circuits used in previous studies of finite element method is not required. When the dimensions and characteristics of core is defined, the nonlinear characteristics of core, which are dependent on its material, are added to the model. With the definition of the core model and its material, windings and boundary conditions, as well as interesting electrical circuit, the desired model is provided.

\section{SIMULATION RESULTS}

Firstly, the normal working condition of transformer is simulated. Figure 6 shows the normal working current of transformer and Figure 7 depicts transformer magnetizing inrush at the starting time. It is obvious that magnetizing inrush at starting time is created due to non-linear nature of the core and after passing a short time, magnetizing inrush becomes attenuated and reaches to a steady state.

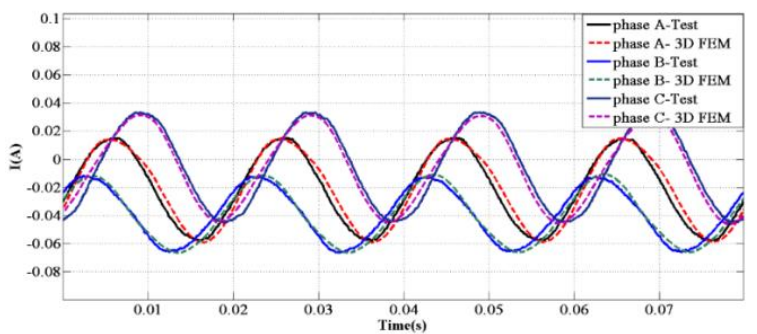

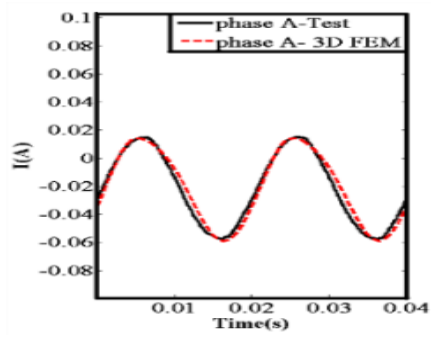

Phase A

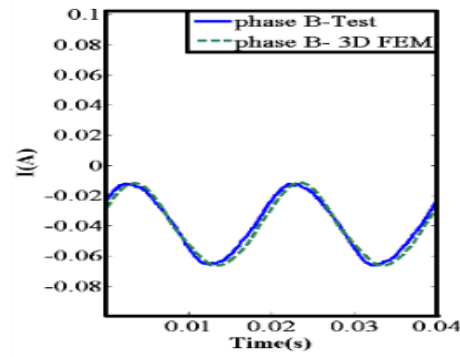

Phase B

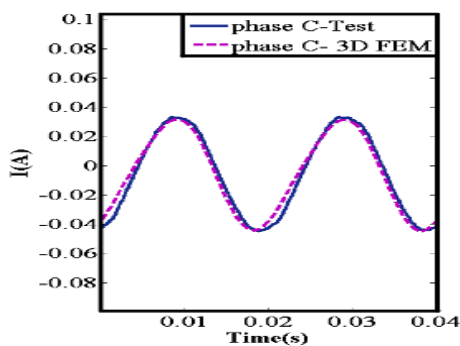

Phase C

Figure 6. Current Value in the Transformer Normal Working Condition 


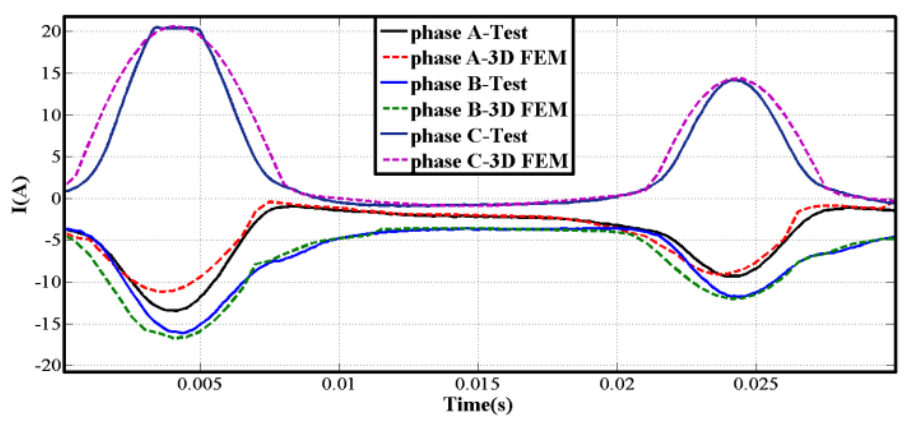

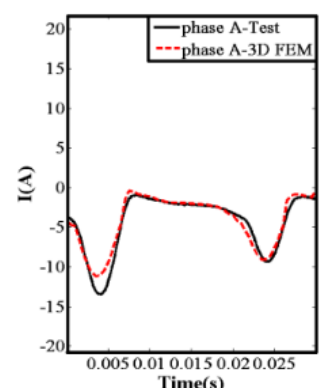

Phase A

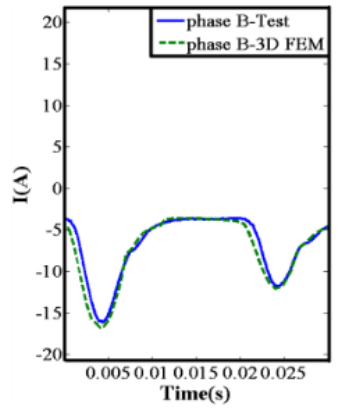

Phase B

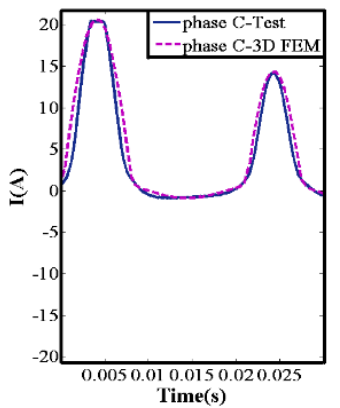

Phase C

Figure 7. Magnetizing Inrush

In this paper, three types of simulation including 1- primary to secondary phase winding fault, turn to turn fault and simultaneous turn to turn fault in two phase and three phase, are studied. Because the supply is an ideal sinusoidal, the value of initial voltage is same as the supply value. Because the secondary side is an open circuit, the value of the secondary side current is equal to zero. Therefore, only the secondary side currents are illustrated. The short circuit fault occurrence time in all types of simulation is considered as $1 \mathrm{sec}$ and the short circuit resistance is $0.3 \mathrm{ohm}$ which describes switch resistance and contactor blades resistance.

When a an internal short circuit fault occurs in secondary winding of transformer, both in turn to earth short circuit fault and turn to turn fault, the former would increase and a huge eddy current in connection meshes would flow. Figure 8 shows turn to turn short circuit in phase a when the 98th turn is connected to 182 th of primary side. Due to low frequency study of internal fault, the transient conditions are not depicted in simulations. Figure 9 illustrates simultaneously turn to turn short circuit in phase A and B when the 98th turn is connected to 182th of primary side in phase A and the 98th turn is connected to 182th of primary side in phase $\mathrm{B}$.

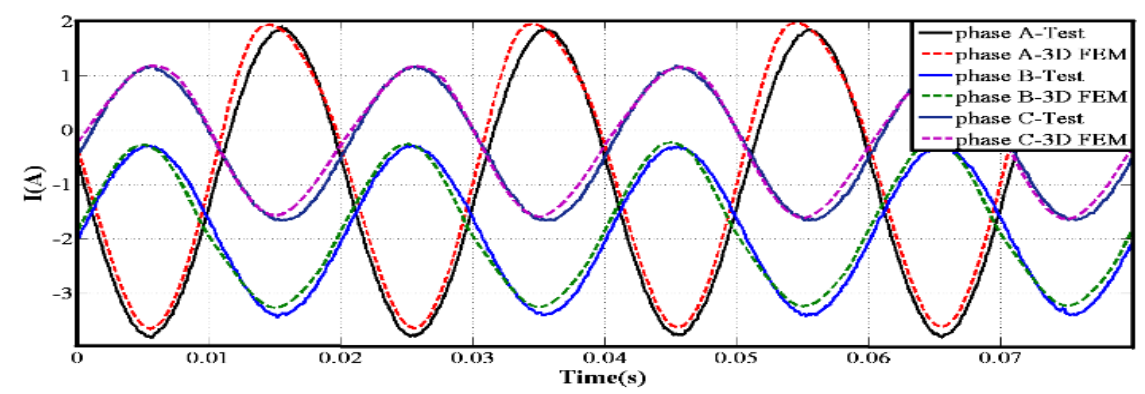




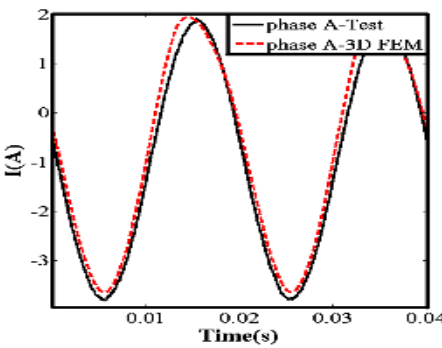

Phase A

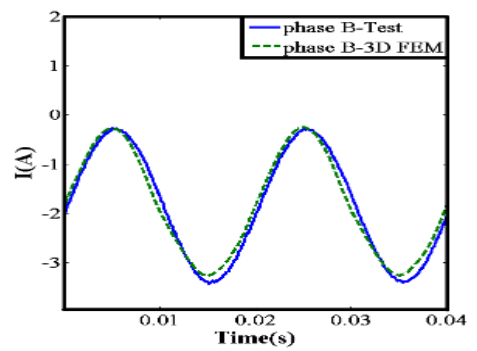

Phase B

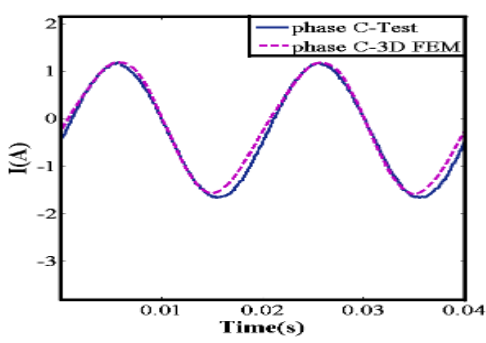

Phase C

Figure 8. Current Value in the Fault Condition

Different fault conditions in transformer have been considered. The simulation results and tests on the practical type transformer are shown in Table. 2. In table 2 and at the first column, $\mathrm{P}$ means primary side and the numbers which are next to the $\mathrm{P}$ depict connection turns to each other and $\mathrm{A}, \mathrm{B}$, and $\mathrm{C}$ illustrate the corresponding faulty phases. The obtained simulation results reveal when an internal fault occurs in the transformer, because supply voltage is constant and the less number of turns should provide the same magnetic motivation force (MMF), therefore the value of current variation is high and incremental. Also the eddy current passing the connection meshes causes a MMF in the mesh which is the opposite of its creator based on Lenz rule and tries to weaken the main MMF. This concept is also another reason about the increase of the current value during the internal short circuit.

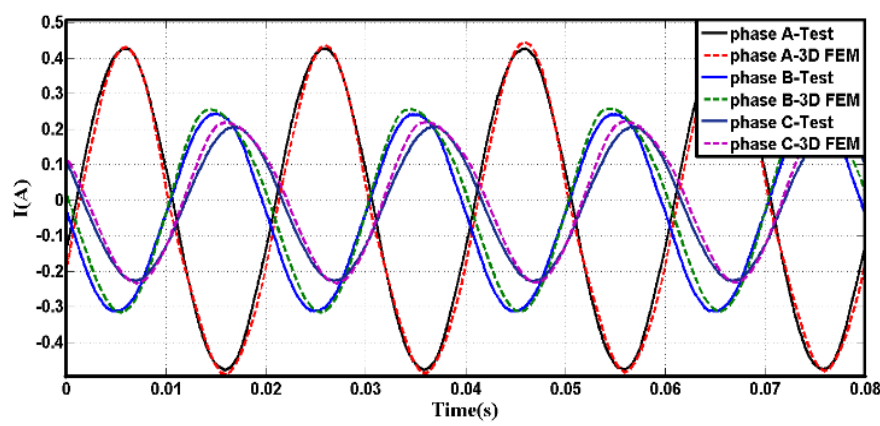

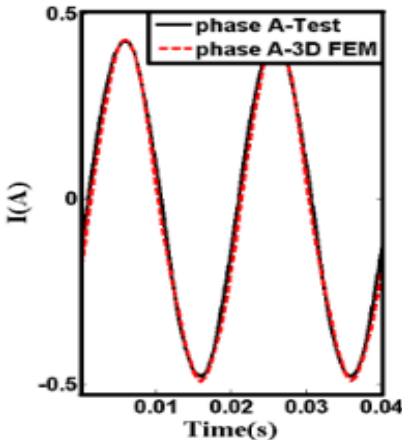

Phase A

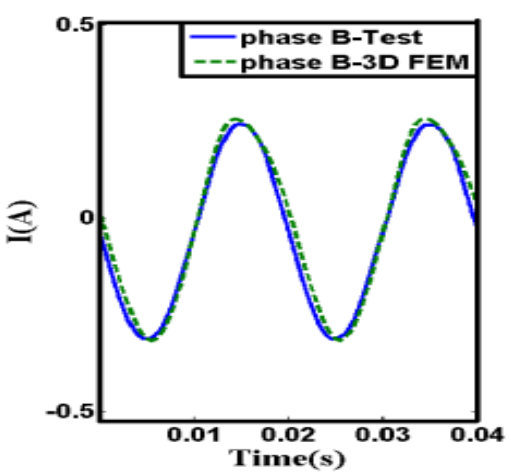

Phase B

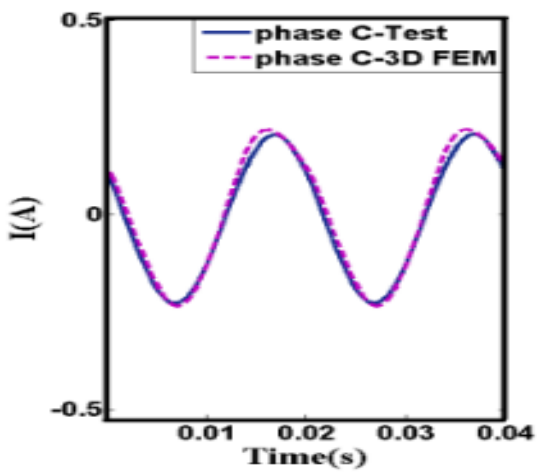

Phase C

Figure 9. Current Value in the Fault Condition 
Table 2.The Comparison of Fault Results

\begin{tabular}{|c|c|c|c|c|c|c|c|c|c|}
\hline \multicolumn{2}{|c|}{ FAULT } & \multirow{3}{*}{$\begin{array}{c}\mathrm{I}_{\text {phase A }} \\
0.7916 \\
0.8001\end{array}$} & \multirow{3}{*}{$\begin{array}{c}I_{\text {phase B }} \\
0.5256 \\
0.5263\end{array}$} & \multirow{3}{*}{$\begin{array}{c}\mathrm{I}_{\text {phase C }} \\
0.3982 \\
0.3991\end{array}$} & \multicolumn{2}{|c|}{ FAULT } & \multirow{3}{*}{$\begin{array}{c}\mathrm{I}_{\text {phase A }} \\
3.2067 \\
3.1564\end{array}$} & \multirow{3}{*}{$\begin{array}{c}\mathrm{I}_{\text {phase B }} \\
1.7643 \\
1.8121\end{array}$} & \multirow{3}{*}{$\begin{array}{c}I_{\text {phase C }} \\
1.5925 \\
1.6458\end{array}$} \\
\hline $\mathrm{P} 266-252(\mathrm{~A})$ & TEST & & & & & TEST & & & \\
\hline P266-252(A) & SIMULATION & & & & P98-56(A) & SIMULATION & & & \\
\hline \multirow{2}{*}{ P252-238(A) } & TEST & 0.6957 & 0.4517 & 0.3702 & \multirow{2}{*}{ P70-28(A) } & TEST & 3.8545 & 2.1310 & 1.889 \\
\hline & SIMULATION & 0.6992 & 0.4523 & 0.3747 & & SIMULATION & 3.8111 & 2.1002 & 1.9785 \\
\hline \multirow{2}{*}{ P238-224(A) } & TEST & 0.8093 & 0.5024 & 0.3922 & \multirow{2}{*}{ P56-14(A) } & TEST & 3.8216 & 2.2858 & 2.2376 \\
\hline & SIMULATION & 0.8055 & 0.5111 & 0.3888 & & SIMULATION & 3.1546 & 2.3154 & 2.2001 \\
\hline \multirow{2}{*}{ P224-210(A) } & TEST & 0.8685 & 0.5469 & 0.4325 & \multirow{2}{*}{ P182-98(A) } & TEST & 6.2299 & 3.2924 & 3.1055 \\
\hline & SIMULATION & 0.8564 & 0.5399 & 0.4233 & & SIMULATION & 6.1546 & 3.3121 & 3.0987 \\
\hline \multirow{2}{*}{ P210-196(A) } & TEST & 0.8341 & 0.5233 & 0.4194 & \multirow{2}{*}{$\mathrm{P} 140-56(\mathrm{~A})$} & TEST & 5.6613 & 3.2878 & 2.8375 \\
\hline & SIMULATION & 0.8215 & 0.5123 & 0.4211 & & SIMULATION & 5.74561 & 3.3145 & 2.9125 \\
\hline \multirow{2}{*}{ P196-182(A) } & TEST & 0.9279 & 0.5778 & 0.4861 & \multirow{2}{*}{ P98-14(A) } & TEST & 7.9117 & 3.924 & 3.6987 \\
\hline & SIMULATION & 0.9398 & 0.5698 & 0.4911 & & SIMULATION & 7.8456 & 3.8889 & 3.6015 \\
\hline \multirow{2}{*}{ P182-168(A) } & TEST & 0.8541 & 0.552 & 0.4367 & $\begin{array}{l}\text { P266- } \\
\text { 252(B) }\end{array}$ & TEST & 0.7634 & 0.4745 & 0.3968 \\
\hline & SIMULATION & 0.8479 & 0.5436 & 0.4299 & $\begin{array}{l}\text { P266- } \\
\text { 252(A) }\end{array}$ & SIMULATION & 0.7548 & 0.4569 & 0.4021 \\
\hline \multirow{2}{*}{ P168-154(A) } & TEST & 0.8824 & 0.553 & 0.546 & $\begin{array}{l}\text { P266- } \\
252(B)\end{array}$ & TEST & 0.9032 & 0.5552 & 0.4347 \\
\hline & SIMULATION & 0.8546 & 0.5412 & 0.5399 & $\begin{array}{l}\text { P224- } \\
210(\mathrm{~A})\end{array}$ & SIMULATION & 0.8954 & 0.5123 & 0.4125 \\
\hline \multirow{2}{*}{ P154-140(A) } & TEST & 0.9 & 0.5639 & 0.4891 & $\begin{array}{l}\text { P154- } \\
140 \text { (B) }\end{array}$ & TEST & 0.7792 & 0.5052 & 0.4671 \\
\hline & SIMULATION & 0.8989 & 0.5566 & 0.4789 & $\begin{array}{l}\text { P224- } \\
210(\mathrm{~A})\end{array}$ & SIMULATION & 0.7859 & 0.5121 & 0.4556 \\
\hline \multirow[b]{2}{*}{ P140-126(A) } & TEST & 0.7881 & 0.5057 & 0.3867 & P154- & TEST & 0.7920 & 0.4961 & 0.4841 \\
\hline & SIMULATION & 0.7979 & 0.5121 & 0.3911 & $\begin{array}{c}140(\mathrm{~B}) \\
\text { P84-70(A) }\end{array}$ & SIMULATION & 0.8012 & 0.5012 & 0.4752 \\
\hline \multirow{3}{*}{ P126-112(A) } & TEST & 0.7358 & 0.4669 & 0.3379 & $\begin{array}{l}\text { P182- } \\
140(B)\end{array}$ & TEST & 6.6312 & 3.7485 & 3.5887 \\
\hline & SIMULATION & 0.7215 & 0.4545 & 0.3321 & $\begin{array}{c}\text { P266- } \\
154(\mathrm{~A})\end{array}$ & SIMULATION & 6.6123 & 3.7695 & 3.5021 \\
\hline & TEST & 0.8642 & 0.5444 & 0.4064 & P182- & TEST & 3.6691 & 2.3295 & 1.9249 \\
\hline \multirow[t]{2}{*}{ P112-98(A) } & SIMULATION & 0.8569 & 0.5332 & 0.3999 & $\begin{array}{c}140(\mathrm{~B}) \\
\text { P28-70(A) }\end{array}$ & SIMULATION & 3.5656 & 2.2999 & 1.9562 \\
\hline & TEST & 0.8844 & 0.5632 & 0.4779 & $\begin{array}{l}\text { P266- } \\
224(\mathrm{~B})\end{array}$ & TEST & 3.1349 & 1.8799 & 1.8547 \\
\hline P98-84(A) & SIMULATION & 0.8749 & 0.5544 & 0.4899 & $\begin{array}{l}\text { P266- } \\
224(\mathrm{~A})\end{array}$ & SIMULATION & 3.2154 & 1.9102 & 1.8021 \\
\hline P84-70(A) & $\begin{array}{c}\text { TEST } \\
\text { SIMULATION }\end{array}$ & $\begin{array}{l}0.9108 \\
0.9045\end{array}$ & $\begin{array}{l}0.5794 \\
0.5564\end{array}$ & $\begin{array}{l}0.4579 \\
0.4418\end{array}$ & $\begin{array}{c}\text { P266- } \\
\text { P266(A-B) }\end{array}$ & $\begin{array}{c}\text { TEST } \\
\text { SIMULATION }\end{array}$ & $\begin{array}{l}12.9413 \\
12.8556\end{array}$ & $\begin{array}{l}7.2009 \\
7.1556\end{array}$ & $\begin{array}{l}6.6896 \\
6.6052\end{array}$ \\
\hline & TEST & 0.925 & 0.5855 & 0.4342 & $\begin{array}{l}\text { P266- } \\
\text { 252(B) }\end{array}$ & TEST & 0.1032 & 0.1572 & 0.2032 \\
\hline P70-56(A) & SIMULATION & 0.9154 & 0.5748 & 0.4216 & $\begin{array}{l}\text { P266- } \\
252(\mathrm{C}) \\
\text { P266- } \\
252(\mathrm{~A})\end{array}$ & SIMULATION & 0.1121 & 0.1611 & 0.2121 \\
\hline & TEST & 0.884 & 0.5725 & 0.4096 & $\begin{array}{l}\text { P224- } \\
210(\mathrm{~A})\end{array}$ & TEST & 0.7768 & 0.4394 & 0.4329 \\
\hline P56-42(A) & SIMULATION & 0.8798 & 0.5621 & 0.4011 & $\begin{array}{c}\text { P84_70(B) } \\
\text { P154- } \\
140(\mathrm{C})\end{array}$ & SIMULATION & 0.7899 & 0.4499 & 0.4123 \\
\hline & TEST & 0.8656 & 0.5585 & 0.4119 & $\begin{array}{l}\text { P266- } \\
168(A)\end{array}$ & TEST & 6.8032 & 3.7195 & 3.6703 \\
\hline P42-28(A) & SIMULATION & 0.8569 & 0.5365 & 0.4215 & $\begin{array}{l}\text { P184- } \\
140(B) \\
\text { P266- } \\
252(\mathrm{C})\end{array}$ & SIMULATION & 6.7456 & 3.7215 & 3.6021 \\
\hline P28-14(A) & TEST & 0.8047 & 0.5459 & 0.6403 & $\begin{array}{l}\text { P266- } \\
210(A)\end{array}$ & TEST & 4.2506 & 1.7988 & 2.7315 \\
\hline $120-1$ (2) & SIMULATION & 0.8145 & 0.5124 & 0.6321 & $\begin{array}{c}\text { P140-84(B) } \\
\text { P14-70(C) }\end{array}$ & SIMULATION & 4.3201 & 1.8012 & 2.8024 \\
\hline P266-224(A) & TEST & 3.2717 & 1.8501 & 1.6653 & $\begin{array}{l}\text { P210-70(B) } \\
\text { P140-14(C) }\end{array}$ & TEST & 11.6251 & 4.1281 & 8.1978 \\
\hline 1200 22 (A2) & SIMULATION & 3.3656 & 1.8052 & 1.6122 & $\begin{array}{l}\text { P266- } \\
140(\mathrm{~A})\end{array}$ & SIMULATION & 11.6025 & 4.2211 & 8.2012 \\
\hline
\end{tabular}


All the numerical results in the table are based on domain. The comparison between simulation results shows that most of the time, the transformer modeling in the internal short circuit condition using 3D structural finite element method presents high accuracy of transformer behavior. So, the performance of power transformer in protection studies and especially internal faults with high reliability is provided by using 3D structural finite element method which is proposed and investigated in this contribution.

\section{CONCLUSION}

In this paper, an approach-based on study of internal winding short circuit faults of three phase transformer with using 3D finite element method is investigated. Based on practical information of transformer, the finite element model for internal short circuit fault condition is carried out by using COMSOL Multiphysics software. Based on this model, by determining the dimensions, the material of producer elements and electrical connections between transformer components and with numerical solution in magnetic area and obtaining the flow flux, the values of current and voltages in transformer are calculated. Also, for determining the faults in transformer, after entering the characteristics and dividing the faulty coil into some parts, the existing faults are applied in the transformer and with the mentioned numerical approach, the problem has been solved.

Also in order to have more studies about the efficiency of proposed approach and showing its robustness, different conditions of internal faults are simulated and various practical tests are performed on a typical transformer in the laboratory. With entering the transformer characteristics into the program and making the transformer model, the current and voltage values are assessed. The comparison between simulation results and obtained experimental results reveals that the modeling of transformer by using 3D finite element method presents an accurate approximation of terminal values of transformer in the normal condition, magnetizing inrush and internal faults. This model can be used in different algorithms which are needed for utilizing protection of power transformers.

\section{REFERENCES}

[1] Franklin, Arthur Charles, and David Peter Franklin. The J \& P transformer book: a practical technology of the power transformer. Elsevier, 2013.

[2] Oliveira, Luís MR. "A permeance-based transformer model and its application to winding interturn arcing fault studies." Power Delivery, IEEE Transactions on 25.3 (2010): 1589-1598.

[3] G. Eason, B. Noble, and I.N. Sneddon, "On certain integrals of Lipschitz-Hankel type involving products of Bessel functions, ” Phil. Trans. Roy. Soc. London, vol. A247, pp. 529-551, April 1955.

[4] Pedra, Joaquin, et al. "Harmonic nonlinear transformer modeling." Power Delivery, IEEE Transactions on 19.2 (2004): 884-890.

[5] Greene, J. David, and Charles Gross. "Nonlinear modeling of transformers."Industry Applications, IEEE Transactions on 24.3 (1988): 434-438.

[6] Morched, A., L. Marti, and J. Ottevangers. "A high frequency transformer model for the EMTP." Power Delivery, IEEE Transactions on 8, no. 3 (1993): 1615-1626.

[7] Phadke, A.G., Thorp, J.S. (1983). "A new computer-based flux-restrained current-differential relay for power transformer protection". IEEE Trans. on Power App. System, Vol. PAS-102, no. 11, pp. 3624-3629.

[8] Rahman, M., and B. Jeyasurya. "A state-of-the-art review of transformer protection algorithms." IEEE transactions on power delivery 3, no. 2 (1988): 534-544.

[9] Larson, R. R., A. J. Flechsig, and E. O. Schweitzer. "The design and test of a digital relay for transformer protection." Power Apparatus and Systems, IEEE Transactions on 3 (1979): 795-804.

[10] Inagaki, Keizo, Masaru Higaki, Yoshiaki Matsui, Kentaro Kurita, Mamoru Suzuki, Kazuyoshi Yoshida, and Takafumi Maeda. "Digital protection method for power transformers based on an equivalent circuit composed of inverse inductance." Power Delivery, IEEE Transactions on 3, no. 4 (1988): 1501-1510.

[11] Bertrand, P., A. Devalland, and P. Bastard. "A simulation model for transformer internal faults base for the study of protection and monitoring systems." In Electricity Distribution, 1993. CIRED. 12th International Conference on, pp. 1-21. IET, 1993.

[12] Bastard, Pauick, Pierre Bertrand, and Michel Meunier. "A transformer model for winding fault studies." Power Delivery, IEEE Transactions on 9, no. 2 (1994): 690-699.

[13] Wang, Huifang, and K. L. Butler. "Finite element analysis of internal winding faults in distribution transformers." Power Delivery, IEEE Transactions on 16, no. 3 (2001): 422-428.

[14] Wang, Hang, Peter Palmer-Buckle, and Karen L. Butler. "Transformer models for detection of incipient internal winding faults." In Proceedings of the 30th North American power symposium, October, Cleveland, OH, pp. 90-98. 1998.

[15] Liu, Z., S. Liu, and O. A. Mohammed. "A practical method for building the FE-based phase variable model of single phase transformers for dynamic simulations. " Magnetics, IEEE Transactions on 43, no. 4 (2007): 1761-1764.

[16] Liu, S., Z. Liu, and O. A. Mohammed. "FE-based modeling of single-phase distribution transformers with winding short circuit faults." Magnetics, IEEE Transactions on 43, no. 4 (2007): 1841-1844. 
[17] Ozgonenel, Okan, and Erdal Kilic. "Modeling and real-time fault identification in transformers." Journal of the Franklin Institute 345, no. 3 (2008): 205-225.

[18] Srelatha, G., M. Rajkumar, Y. Sudhakar, and T. K. Ganguly. "Improvements in Internal Insulation Design of Power Transformer using Electric Field Analysis Through Finite Element Method." Power Engineer Journal 16, no. 2 (2014): 56-60.

[19] da Silva, Juliano Ricardo, Joao P. Bastos, Nelson Sadowsky, and Jean V. Leite. "Electromagnetic and thermal simulation of an oil insulated power transformer." In Electrical Apparatus and Technologies (SIELA), 2014 18th International Symposium on, pp. 1-4. IEEE, 2014.

[20] Behjat, V., Vahedi, A. "Numerical modeling of transformers inturn faults and characterizing the faulty transformer behaviour under various faults and operating conditions". IET Electic Power App, Vol. 5, (2011) pp. 415-431.

[21] Piriou, F., and A. Razek. "Numerical simulation of a nonconventional alternator connected to a rectifier." Energy Conversion, IEEE Transactions on 5, no. 3 (1990): 512-518.

[22] Bouissou, S., F. Piriou, C. Kieny, and G. Tanneau. "Numerical simulation of a power transformer using 3D finite element method coupled to circuit equation."Magnetics, IEEE Transactions on 30, no. 5 (1994): 3224-3227.

[23] COMSOL, MULTIPHASICS (C) (FEMLAB), [online]. http://www.comsol.com 